\title{
Evaluation of the AMSR2 L2 soil moisture product of JAXA on the Mongolian Plateau over seven years (2012-2018)
}

\author{
Ichirow Kaihotsu ${ }^{1} \cdot$ Jun Asanuma ${ }^{2} \cdot K$ entaro Aida ${ }^{3} \cdot$ Dambaravjaa Oyunbaatar $^{4}$
}

Received: 27 July 2019 / Accepted: 11 October 2019 / Published online: 24 October 2019

(C) The Author(s) 2019 OPEN

\begin{abstract}
This study evaluated the Advanced Microwave Scanning Radiometer 2 (AMSR2) L2 soil moisture product (ver. 3) using in situ hydrological observational data, acquired over 7 years (2012-2018), from a $50 \times 50 \mathrm{~km}$ flat area of the Mongolian Plateau covered with bare soil, pasture and shrubs. Although AMSR2 slightly underestimated soil moisture content at 3-cm depth, satisfactory timing was observed in both the response patterns and the in situ soil moisture data, and the differences between these factors were not large. In terms of the relationship between AMSR2 soil moisture from descending orbits and in situ measured soil moisture at 3-cm depth, the values of the RMSE $\left(\mathrm{m}^{3} / \mathrm{m}^{3}\right)$ and the bias $\left(\mathrm{m}^{3} / \mathrm{m}^{3}\right)$ varied from 0.028 to 0.063 and from 0.011 to $-0.001 \mathrm{~m}^{3} / \mathrm{m}^{3}$, respectively. The values of the RMSE and bias depended on rainfall condition. The mean value of the RMSE for the 7 -year period was $0.042 \mathrm{~m}^{3} / \mathrm{m}^{3}$, i.e., lower than the target accuracy $0.050 \mathrm{~m}^{3} / \mathrm{m}^{3}$. The validation results for descending orbits were found slightly better than for ascending orbits. Comparison of the Soil Moisture and Ocean Salinity (SMOS) soil moisture product with the AMSR2 L2 soil moisture product showed that AMSR2 could observe surface soil moisture with nearly same accuracy and stability. However, the bias of the AMSR2 soil moisture measurement was slightly negative and poorer than that of SMOS with deeper soil moisture measurement. It means that AMSR2 cannot effectively measure soil moisture at 3-cm depth. In situ soil temperature at 3-cm depth and surface vegetation (normalized difference vegetation index) did not influence the underestimation of AMSR2 soil moisture measurements. These results suggest that a possible cause of the underestimation of AMSR2 soil moisture measurements is the difference between the depth of the AMSR2 observations and in situ soil moisture measurements. Overall, this study proved the AMSR2 L2 soil moisture product has been useful for monitoring daily surface soil moisture over large grassland areas and it clearly demonstrated the high-performance capability of AMSR2 since 2012.
\end{abstract}

Keywords Soil moisture $\cdot$ AMSR2 $\cdot$ SMOS $\cdot$ Climate change $\cdot$ Mongolian Plateau

\section{Introduction}

It is exceedingly important to study soil moisture behavior within the context of the hydrological cycle, and with respect to climate change and global warming [1]. In particular, this behavior influences surface natural environments in semiarid and arid areas with highly variable rainfall both spatially and temporally. However, it is not easy to determine clear mechanisms of soil moisture change in such areas over large scales using traditional in situ observation methods; thus, satisfactory scientific information regarding soil moisture behavior has not yet been obtained. The primary difficulty in using traditional in situ observation techniques is the impracticality

$\triangle$ Ichirow Kaihotsu, kaihotu@hiroshima-u.ac.jp; Jun Asanuma, asanuma@ied.tsukuba.ac.jp; Kentaro Aida, aida-k677bt@pwri.go.jp; Dambaravjaa Oyunbaatar, oytetuarel@yahoo.com | ${ }^{1}$ Graduate School of Integrated Arts and Sciences, Hiroshima University, Hiroshima 7308521, Japan. ${ }^{2}$ Center for Research in Isotopes and Environmental Dynamics (CRiED), University of Tsukuba, Tsukuba, Ibaraki 3058577, Japan. ${ }^{3}$ International Centre for Water Hazard and Risk Management (ICHARM), Tsukuba, Ibaraki 3058516, Japan. ${ }^{4}$ Research and Information Institute of Meteorology, Hydrology, and Environment, Ulaanbaatar 14201, Mongolia. 
of conducting reliable large-scale long-term monitoring. Potentially, satellite-derived observations of soil moisture offer an effective alternative, and a number of satellites such as the Aqua and Soil Moisture and Ocean Salinity (SMOS) satellites have actually succeeded in monitoring surface soil moisture $[2,3]$.

The Global Change Observation Mission (GCOM) of the Japan Aerospace Exploration Agency (JAXA) is a project designed for global long-term observation of the environment in relation to the meteorology and the hydrology of the Earth [4]. GCOM consists of two satellites: GCOM-C that is intended for monitoring the climate and GCOM-W that is intended for monitoring the global water cycle. JAXA launched GCOM-W1 (GCOM 1st-Water: renamed later as GCOM-W) on May 18, 2012. GCOM-W1 is equipped with the Advanced Microwave Scanning Radiometer 2 (AMSR2), which globally observes surface soil moisture (soil moisture from the surface to several $\mathrm{cm}$ depth), as well as other water-related parameters such as precipitation, water vapor and snow depth. Theoretically, AMSR2 is able to acquire a set of daytime and nighttime data with $>99 \%$ coverage of the Earth every 2 days [5]. The basic concept of the instrumentation of AMSR2 is very similar to that of the Advanced Microwave Scanning Radiometer for the Earth Observing System (AMSR-E), observing at frequency bands of 6.925, 7.3, 10.65, 18.7, 23.8, 36.5 and 89.0 GHz [4]. The AMSR-E soil moisture data have been proven highly useful for studies of drought and global-regional water cycle change [6, 7]. AMSR2 is the successor to the AMSR on ADEOS II and the AMSR-E on Aqua [8]. Since its launch, GCOM-W1 has remained in orbit at an altitude of approximately $700 \mathrm{~km}$, during which time it has measured daily global soil moisture on the surface of the Earth with target accuracy of $0.05 \mathrm{~m}^{3} /$ $\mathrm{m}^{3}$ [5] giving spatial resolution better than $50 \mathrm{~km}$. This orbit was adopted to maintain consistency with AMSR-E, and thus GCOM-W1 has been participating in the A-Train satellite constellation [9]. This enhances the synchronous measurement capability with other satellite instruments available within the constellation. AMSR2 has been successful in monitoring soil moisture globally on a daily basis since its launch and data from the AMSR2 L2 soil moisture products are available from the JAXA GCOM-W Web site [5].

It is necessary to assess the reliability and accuracy of AMSR2 soil moisture data to enable precise validation and/ or evaluation in as many different areas as possible. To determine the measurement accuracy of AMSR2 soil moisture, further evaluation should be conducted using the latest version of the AMSR2 soil moisture product at various sites with different surface conditions and sizes. One previous study evaluated the AMSR2 L2 soil moisture products (ver. 0) over a $60 \times 60 \mathrm{~km}$ area around Yanco in the Murrumbidgee River catchment in New South Wales (Australia) [10]. The Yanco area is generally flat with irrigation and cropping areas [11]. The results of that study showed that the averaged value of the root mean square deviation for both 10and $25-\mathrm{km}$ products was $0.05 \mathrm{~m}^{3} / \mathrm{m}^{3}$. Subsequently, other studies have conducted validation of the AMSR2 soil moisture products in many sites in Asia, Europe, Australia and the USA [12-18]. These studies showed that AMSR2 has certain characteristics such as negative bias and variation of the RMSE that have not been discussed fully. Moreover, the sampling depth of in situ soil moisture measurements should also be investigated because in situ soil moisture data at 5-cm depth and cosmic-ray soil moisture observing system (COSMOS) network data with changeable measurement depth depending on the moisture condition of the soils [14] have generally been used for validation since 2012 . Furthermore, validation of long-term ASMR2 measurements over periods longer than 3 years has not been conducted.

As the AMSR2 frequencies used for soil moisture measurements are higher than the L-band $(1.4 \mathrm{GHz})$, their penetration depths are relatively shallower than SMOS and SMAP [19, pp. 136-139]. In particular, Escorihuela et al. [20] highlighted that the effective soil moisture sampling depth of L-band radiometry is $0-2 \mathrm{~cm}$. However, at least, validation studies of AMSR2 and SMOS using the longterm data of in situ soil moisture measurement in the surface soil layer of $0-2-\mathrm{cm}$ depth have not been published since 2009. Therefore, it is important to evaluate the potential for using long-term monitoring data of in situ soil moisture at depths shallower than $5 \mathrm{~cm}$.

As part of the Mongol AMSR-E/AMSR2 validation experiment, which is a joint operation between Hiroshima University and/or The University of Tsukuba and JAXA, intensive field observations have been undertaken annually, together with in situ monitoring, over a $1.1^{\circ} \times 1.1^{\circ}$ (about $120 \times 120 \mathrm{~km}$ ) validation site on the Mongolian Plateau for both AMSR-E and AMSR2 soil moisture algorithms. Soil moisture measurements at $3-\mathrm{cm}$ depth have been conducted at many points within this site since 2000 [21]. Evaluations of the L2 soil moisture products of the SMOS and Soil Moisture Active Passive (SMAP) satellites have also been performed using this site, which is considered representative of pastoral areas in central Asia [17, 21]. As mentioned above, AMSR2 has been observing daily global surface soil moisture since 2012. However, as the observation period has now reached 8 years (well beyond the original design life of 5 years), determining the recent performance of AMSR2 soil moisture measurements could be considered indispensable both for studies of the inland effects of climate change and hydrological change and for supporting the development of the forthcoming Advanced Microwave Scanning Radiometer 3 [22].

The purpose of the current study was to evaluate the AMSR2 L2 soil moisture product (ver. 3: the latest version as of December 2018), obtained from both ascending and 
descending orbits, using in situ soil moisture measurements at 3-cm depth and meteorological data collected during 2012-2018 in a study area on the Mongolian Plateau. The results were then compared with the SMOS L2 soil moisture products (ver. 650) in terms of observational stability, measurement accuracy and bias and effective sampling depth.

\section{Data and method}

\subsection{Study area}

Evaluation of the AMSR2 soil moisture products was conducted using a $50 \times 50 \mathrm{~km}$ (one AMSR2 pixel) target area (M1) of a $1.1^{\circ} \times 1.1^{\circ}$ study area on the Mongolian Plateau. Seven water cycle stations set in M1 (Table 1, Fig. 1) for the purpose of validation have been monitoring meteorological and hydrological elements since August 2000. The M1 area is geomorphologically flat, and it is mostly covered with bare soil, pasture and shrubs. Each station was installed with consideration of the representativeness of the surrounding geomorphologic and vegetation conditions. Further details of the surface and hydrological conditions of the M1 area can be found in [23].

As can be seen in Table 1, this study used two automatic weather stations (AWSs) and five automatic stations for soil hydrology (ASSH) for evaluation of the AMSR2 soil moisture measurements. Fundamental elements of meteorology and soil moisture were monitored by the AWSs with a time interval of $30 \mathrm{~min}$. The ASSH monitored soil moisture and soil temperatures bi-hourly at depths of 3 and $10 \mathrm{~cm}$. All of the water cycle station sensors were calibrated and checked relative to a base marker and/or to the Japanese Meteorological Agency standard in the laboratory prior to installation [21].

\subsection{In situ soil moisture measurements}

Time domain reflectometry (TDR) soil moisture probes (TRIME-IT/PICO-32, IMKO) were employed to measure horizontally the in situ volumetric soil moisture content at depths of 3 and $10 \mathrm{~cm}$ at all stations. Although the measurement volume of the TDR probe is shown to correspond to an elliptical column of 0.25 I with $11 \mathrm{~cm}$ of the rod length and $2 \mathrm{~cm}$ the rod spacing [24, p. 8], a minor axis of cross section (ellipse) of the elliptical column is unknown (according to IMKO, it is about $2.0 \mathrm{~cm}$ and it depends on the moisture conditions of the soil: personal communications). Therefore, laboratory calibration tests of a TDR soil moisture probe (TRIME-IT 9141, IMKO) placed horizontally at 3-cm depth in a PVC container filled with soil from the study area were conducted before field installation. The tests showed the TDR probe at 3-cm depth correctly measured soil moisture without atmospheric influence. The in situ soil moisture conditions have been checked by researchers involved in this study at the time of data collection and station maintenance every August or September since 2000 .

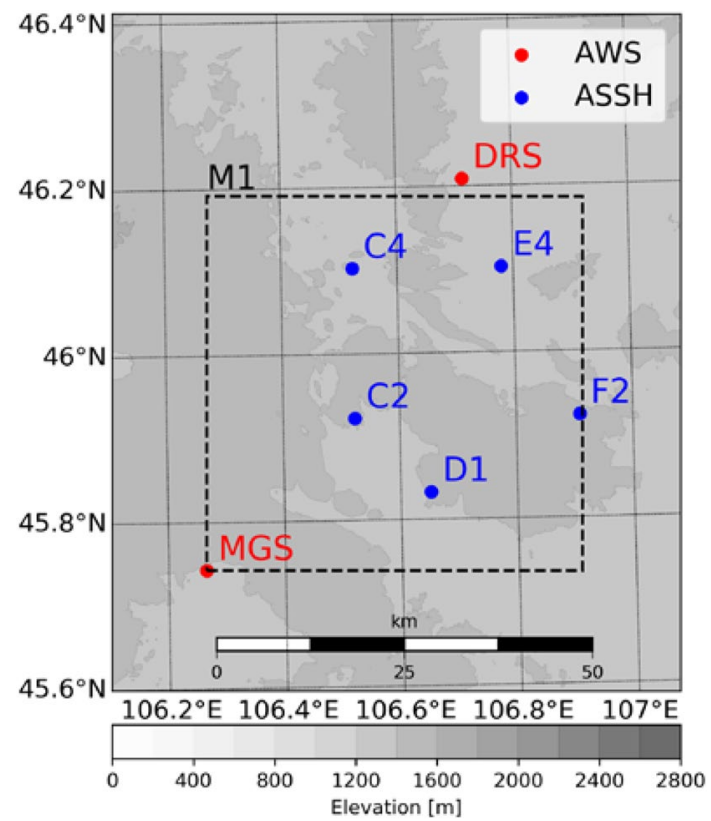

Fig. 1 Study area (M1: target area), automatic weather stations (AWSs) and automatic stations for soil hydrology (ASSH)
Table 1 Automatic weather stations (AWSs) and automatic stations for soil hydrology (ASSH) used for the validation in $\mathrm{M} 1$

\begin{tabular}{llllll}
\hline Station ID & $\begin{array}{l}\text { Measurement } \\
\text { point }\end{array}$ & Lat. (N) & Long. (E) & Alt. (m) & Station type \\
\hline MGS & MGS & $45^{\circ} 44^{\prime} 34.9^{\prime \prime}$ & $106^{\circ} 15^{\prime} 52.2^{\prime \prime}$ & 1393 & AWS \\
DRS & DRS & $46^{\circ} 12^{\prime} 31.2^{\prime \prime}$ & $106^{\circ} 42^{\prime} 53.0^{\prime \prime}$ & 1297 & AWS \\
811 & F2 & $45^{\circ} 55^{\prime} 22.5^{\prime \prime}$ & $106^{\circ} 54^{\prime} 30.2^{\prime \prime}$ & 1450 & ASSH \\
813 & E4 & $46^{\circ} 06^{\prime} 10.0^{\prime \prime}$ & $106^{\circ} 46^{\prime} 47.2^{\prime \prime}$ & 1318 & ASSH \\
817 & D1 & $45^{\circ} 49^{\prime} 58.6^{\prime \prime}$ & $106^{\circ} 39^{\prime} 04.5^{\prime \prime}$ & 1402 & ASSH \\
820 & C2 & $45^{\circ} 55^{\prime} 22.5^{\prime \prime}$ & $106^{\circ} 31^{\prime} 21.2^{\prime \prime}$ & 1422 & ASSH \\
815 & C4 & $46^{\circ} 06^{\prime} 10.0^{\prime \prime}$ & $106^{\circ} 31^{\prime} 21.2^{\prime \prime}$ & 1383 & ASSH \\
\hline
\end{tabular}


The acquisition of data of both soil moisture at $3-\mathrm{cm}$ depth and rainfall by the ASSH and AWSs, respectively, was obtained successfully and almost continuously during the evaluation period of 2012-2018, which permitted evaluation of the soil moisture data obtained by AMSR2 observations from both ascending and descending orbits. Figure 2 shows that soil moisture at $3-\mathrm{cm}$ depth varied widely and frequently with rainfall events. Specifically, soil moisture values ranged from 0.022 to $0.371 \mathrm{~m}^{3} / \mathrm{m}^{3}$ during the observation period, which extended from April to October in each year except 2018. Unfortunately, soil moisture data at C2 from April to September 2 in 2016 were unavailable because of problems with the ASSH battery. The data shown for 2018 are from April to September 6. The parameter $P_{\text {area }}$ is presented as the mean rainfall of the two AWSs.

Table 2 presents the area-averaged mean total rainfall (Total rainfall), area-averaged mean air temperature (Mean air temperature) and area-averaged mean soil moisture at 3-cm depth for the observation period of April-October (July 3 to October in 2012 and April to September 6 in 2018) in each year. According to the AWS observation data, the $M 1$ air temperature varied between +40.3 and $-37.6^{\circ} \mathrm{C}$ during the observation period (2012-2018). The surface soil started to freeze by mid- and late October, and it was frozen completely until March each year. Melting of the frozen surface soil began in early April of each year except 2017. Sometimes, repeated freezing and thawing of the soil occurred in mid-or late April. These values together with those of Table 2 are characteristic of semiarid land.

The annual area-averaged precipitation in $\mathrm{M} 1$ from 2001 to 2017 except for 2007 and 2008 (because of insufficient data in both years) was $112.8 \mathrm{~mm} /$ year. In this study, a year with annual precipitation of $\geq 112.8(<112.8) \mathrm{mm} /$ year was defined as a wet (dry) year. Thus, it can be seen
Table 2 Meteorological conditions in each observation period (April-October except for 2018: April-September 6) from 2012 to 2018 in M1 SM area $_{\text {: }}$ area-averaged soil moisture

\begin{tabular}{llll}
\hline Year & $\begin{array}{l}\text { Total rainfall } \\
(\mathrm{mm})\end{array}$ & $\begin{array}{l}\text { Mean air tempera- } \\
\text { ture }\left({ }^{\circ} \mathrm{C}\right)\end{array}$ & $\begin{array}{l}\text { Mean } \\
\mathrm{SM}_{\text {area }} \\
\left.\mathrm{m}^{3}\right)\end{array}$ \\
\hline 2012 & 161.5 & 13.0 & 0.093 \\
2013 & 185.3 & 12.7 & 0.131 \\
2014 & 103.6 & 13.8 & 0.086 \\
2015 & 82.0 & 13.8 & 0.075 \\
2016 & 103.6 & 13.2 & 0.073 \\
2017 & 110.7 & 14.2 & 0.051 \\
2018 & 138.4 & 16.4 & 0.073 \\
\hline
\end{tabular}

from Table 2 that 2012, 2013 and 2018 were wet years and that 2014, 2015 and 2016 were dry years, whereas the annual area-averaged precipitation of 2017 was close to the threshold value. The wettest (driest) year was 2013 (2015).

The temporal change of the unbiased variance value of in situ soil moisture content at all stations during the observation period was investigated to determine the amount of change of scatter in the observed values. As shown in Fig. 3, the unbiased variance varied between 0.0086 and $1.32 \mathrm{E}-5 \mathrm{~m}^{3} / \mathrm{m}^{3}$; the higher values were observed in rainfall event cases and in early April (except for 2017). In early April, melting of the frozen soil occurs, which probably increases surface soil moisture. The value of the scatter was considered sufficiently near zero during periods without rainfall. The mean values of the unbiased variance of each year were $0.00117 \mathrm{~m}^{3} / \mathrm{m}^{3}$ (2012), $0.00266 \mathrm{~m}^{3} / \mathrm{m}^{3}$ (2013), $0.00092 \mathrm{~m}^{3} / \mathrm{m}^{3}$ (2014), $0.00095 \mathrm{~m}^{3} /$ $\mathrm{m}^{3}$ (2015), $0.00086 \mathrm{~m}^{3} / \mathrm{m}^{3}$ (2016), $0.00041 \mathrm{~m}^{3} / \mathrm{m}^{3}$ (2017), and $0.00086 \mathrm{~m}^{3} / \mathrm{m}^{3}$ (2018). Lower values indicate

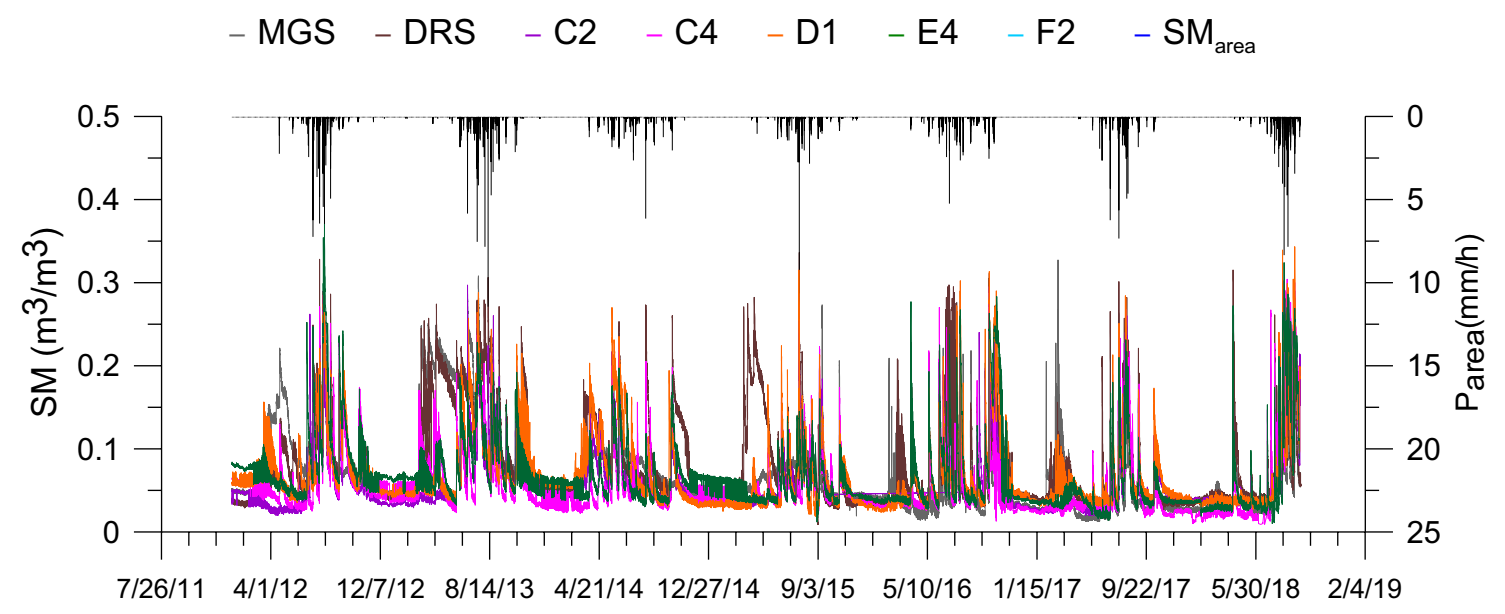

Fig. 2 A time series of soil moisture (SM) of each station, area-averaged soil moisture ( $\mathrm{SM}_{\mathrm{area}}$ : mean value of soil moisture of all the stations) and area-averaged rainfall ( $P_{\text {area: }}$ : mean value of rainfall of two AWS) from April 2012 to September 6, 2018 
(a)

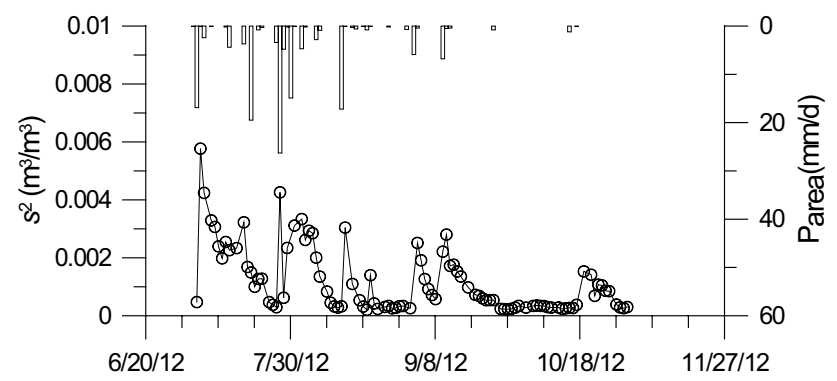

(b)

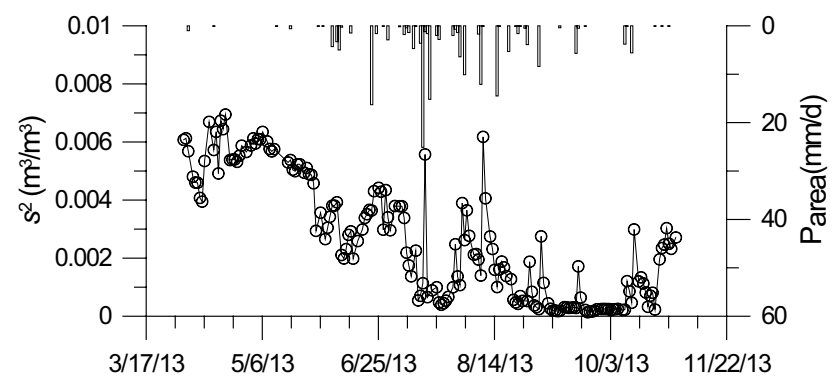

(c)

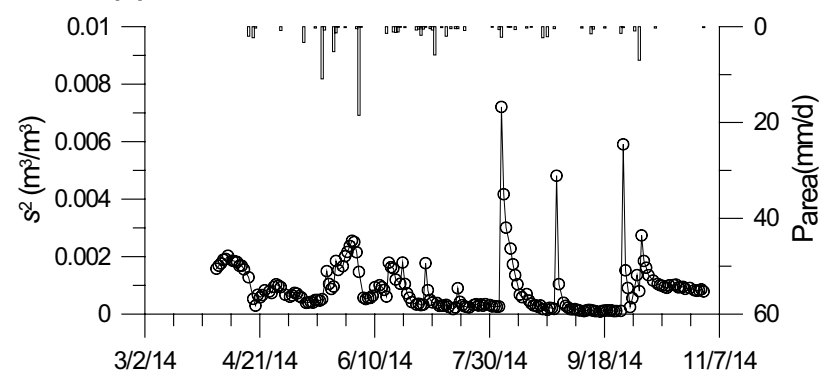

(d)

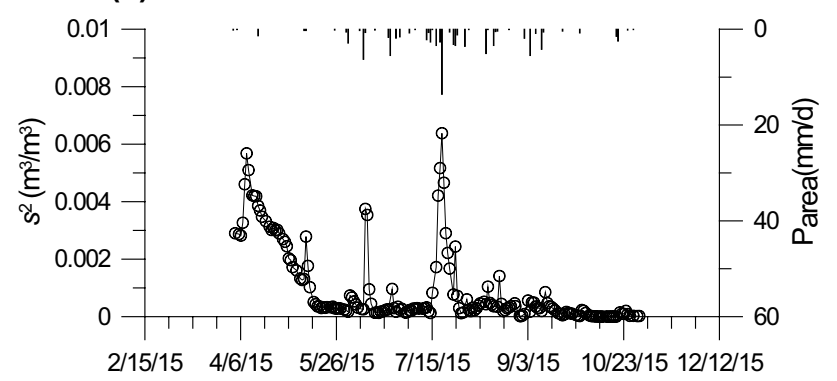

(e)

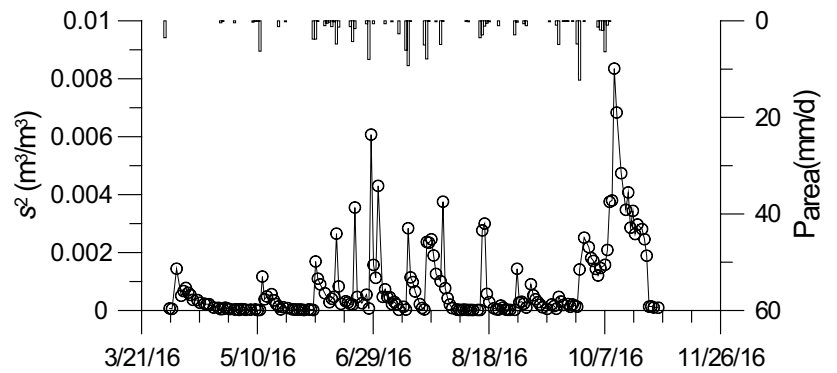

(f)

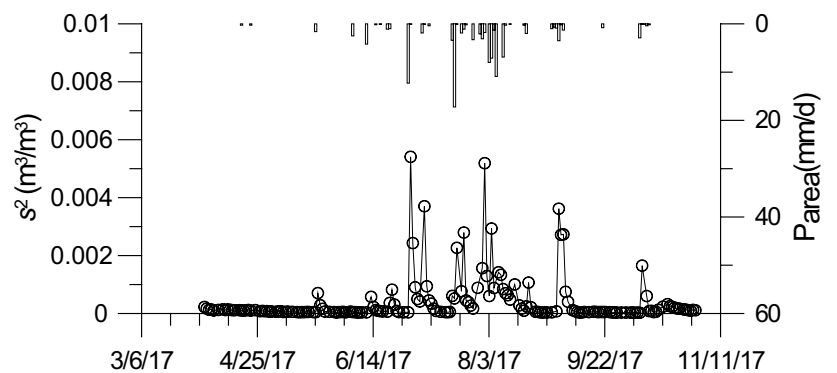

(g)

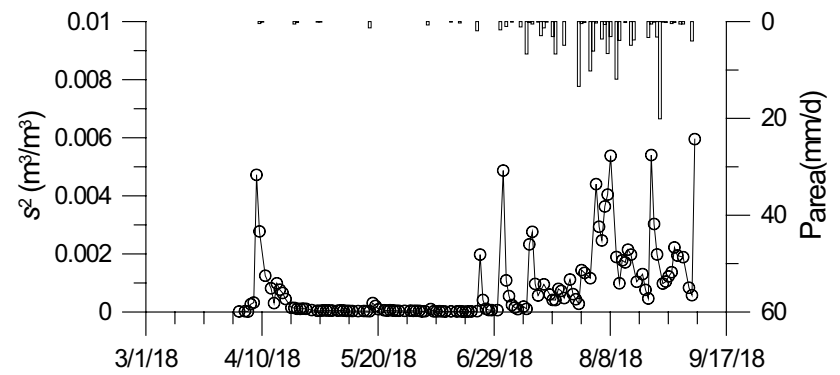

Fig. 3 Time change of the value of the unbiased variance $\left(s^{2}\right)$ of the in situ soil moisture contents of all the stations

improvement in the homogeneity of the distribution of in situ surface soil moisture at 3-cm depth.

Although linear correlation between the amount of daily rainfall recorded by the AWSs at DRS and MGS is evident in Fig. 4, it is not strong. Consequently, because there is certain difference between the observations of the AWSs at DRS and MGS, it could be conjectured that local rainfall of different amounts occurs frequently at the other stations in M1. The results of Figs. 3 and 4 suggest that local rainfall amounts have an effect on the inhomogeneity of the distribution of in situ soil moisture.

\subsection{AMSR2 L2 soil moisture product for evaluation}

AMSR2 observations of soil moisture in M1 on a daily basis are not perfect because the flight overpass path shifts 


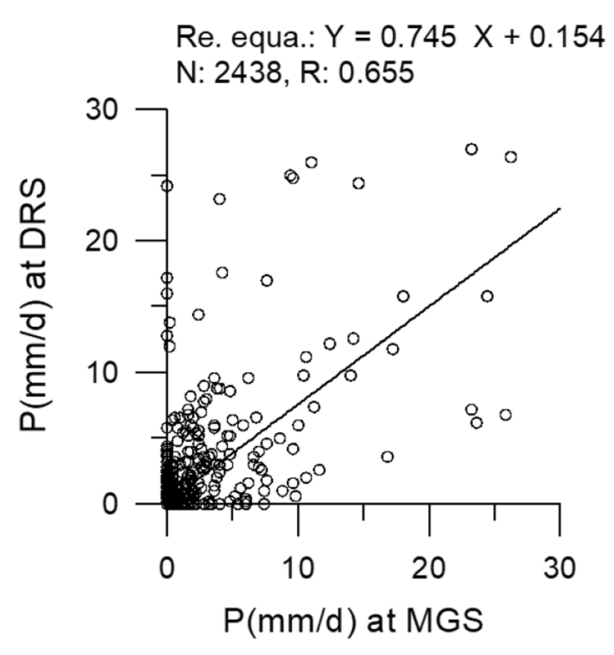

Fig. 4 Relationship of daily rainfall amount (P) between MGS and DRS from 2012 to 2018 ( $N$ : the number of data, R: the correlation coefficient of the linear regression line)

slightly. However, although soil moisture data were not obtained on every day of the observation period, the rate of acquisition of AMSR2 soil moisture data on days when data were obtained was nearly $100 \%$ and the number of days of acquisition during the observation period was $>82 \%$. AMSR2 observations were largely unaffected by radio frequency interference (RFI) during the observation period despite SMOS having known RFI problems [23].

The obtained soil moisture data of all the stations were averaged arithmetically from the available sampling points within M1, and actual data from the AMSR2 L2 soil moisture product were used for the evaluation. In principle, the AMSR2 soil moisture measurement algorithm of [25] is based on Koike's algorithm [26], and it uses the Polar Index $(P I)$ and the Index of Soil Wetness (ISW):

$$
\begin{aligned}
& P I=\frac{T_{b \_v}-T_{b \_h}}{\frac{1}{2}\left(T_{b \_v}+T_{b \_h}\right)} \\
& I S W=\frac{T_{b \_ \text {high }}-T_{b \_l o w}}{\frac{1}{2}\left(T_{b \_ \text {high }}+T_{b \_l o w}\right)}
\end{aligned}
$$

where $T_{b_{\_} v}$ and $T_{b_{-} h}$ are the microwave radiative brightness temperatures of the vertical and horizontal polarizations, respectively. The subscripts high and low in Eq. (2) indicate the frequencies of 36 and $10 \mathrm{GHz}$, respectively. The values of $P I$ and ISW depend primarily on soil moisture and vegetation water content, respectively, rather than on the physical temperature. This is because the effects of the physical temperature can be minimized when dividing by the average brightness temperature. The surface temperature is assumed constant at $293 \mathrm{~K}$. Moreover, this algorithm can also consider the effects of vegetation cover [27]. The use of the $10-\mathrm{GHz}$ frequency means that the size of one pixel of the AMSR2 soil moisture measurement algorithm is approximately $50 \mathrm{~km} \mathrm{[4].} \mathrm{According} \mathrm{to} \mathrm{the} \mathrm{relationship}$ between penetration depth as a function of soil moisture content and the three frequencies of $1.3,4.0$ and $10.0 \mathrm{GHz}$ [19, pp. 136-139], the soil moisture measurement depth is not constant but depends on the total amount of water within the soil layer (soil moisture content) and the measurement frequency. Consequently, AMSR2 might not detect in situ soil moisture for depth $>\sim 4 \mathrm{~cm}$ if using the 10-GHz frequency, as indicated in Eq. (2).

\section{Results and discussion}

\subsection{Comparison of AMSR2 with in situ soil moisture in $\mathrm{M} 1$}

Figure 5 presents comparisons of the AMSR2 L2 soil moisture products, obtained from both ascending and descending orbits, together with in situ area-averaged soil moisture at 3-cm depth in M1. The AMSR2 measured soil moisture on ascending orbits between 13:00 and 15:00 local time and on descending orbits between 02:00 and 04:00 local time. Satisfactory timing is evident in both the response patterns and the in situ soil moisture data, and the differences between these factors are not large. Close inspection of the AMSR2 soil moisture reveals less good response to rainfall events in September 2012 (Fig. 5a), late July to September 2013 (Fig. 5b), and mid-August to early September 2018 (Fig. 5g). In addition, the AMSR2 soil moisture also shows a rapid decrease after reaching a peak in summer. For example, the reductions are particularly rapid in early and mid-September 2012 (Fig. 5a), late July 2013 (Fig. 5b) and late May to early June 2014 (Fig. 5c). Generally, the response of the AMSR2 soil moisture from descending orbits is marginally better than from ascending orbits. In situ soil moisture has an influence on evaporation from the soil surface. Therefore, the correspondence of data from descending orbits is slightly better than from ascending orbits because the measurements were performed overnight.

The poor response of AMSR2 soil moisture during rainfall events, as mentioned above, especially in late July to September 2013 (Fig. 5b) and in mid-August to early September 2018 (Fig. $5 \mathrm{~g}$ ), can be considered attributable to the influence of temporary high soil moisture content and/ or pools of water on the soil surface during rainfall events. Moreover, the AMSR2 soil moisture algorithm cannot eliminate the influence of free water (intercepted rainwater) on plants [28]. Therefore, the effect of free water on plants 
Fig. 5 Comparison of AMSR2 L2 soil moisture product from ascending (A) and descending (D) orbits with in situ area-averaged soil moisture $\left(\mathrm{SM}_{\text {area }}\right)$ at 3-cm depth and area-averaged rainfall $\left(\mathrm{P}_{\text {area }}\right)$ in M1 (2012-2018) red solid line: in situ area-averaged soil moisture, blue open circle: AMSR2 soil moisture from ascending orbits, green solid circle: AMSR2 soil moisture from descending orbits

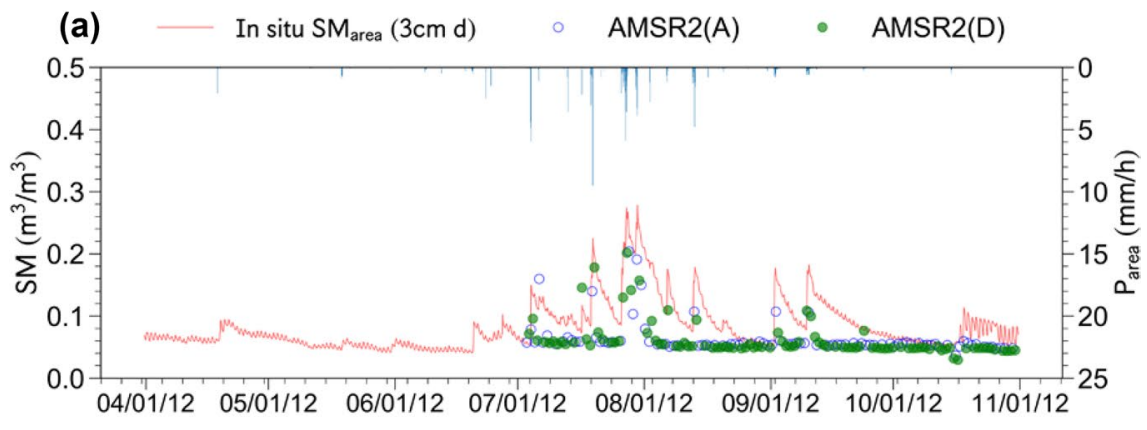

(b) - In situ SMarea $(3 \mathrm{~cm}$ d) $\quad \circ \quad \mathrm{AMSR2}(\mathrm{A}) \quad \mathrm{AMSR2(D)}$

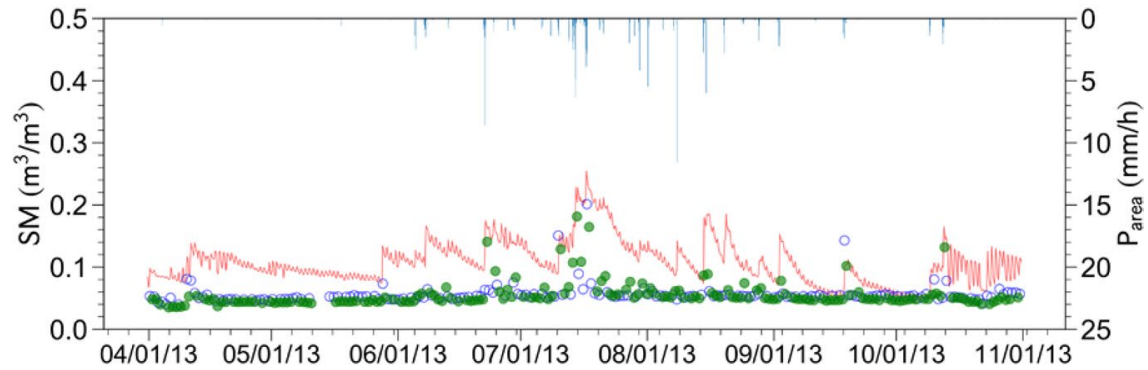

(c) - In situ SMarea $(3 \mathrm{~cm} \mathrm{~d}) \quad \circ \quad \mathrm{AMSR} 2(\mathrm{~A}) \quad$ AMSR2(D)

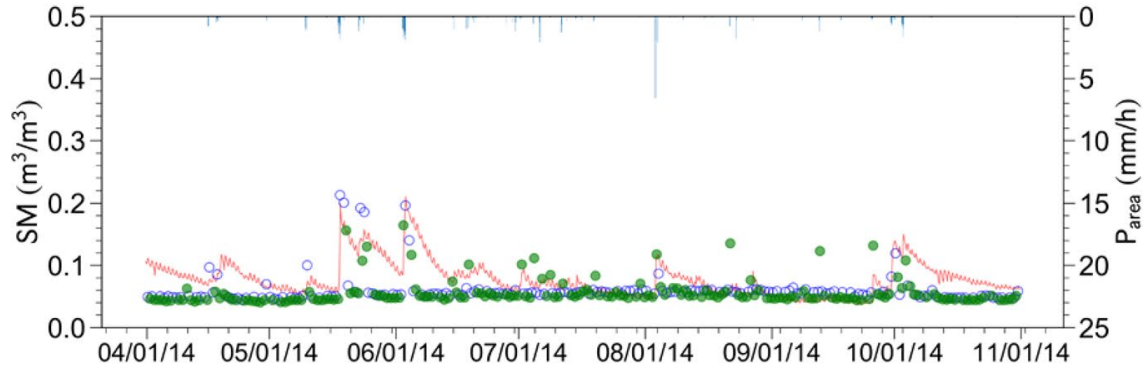

(d) In situ $\mathrm{SM}_{\text {area }}(3 \mathrm{~cm}$ d) $\quad \circ$ AMSR2(A) $\quad$ AMSR2(D)

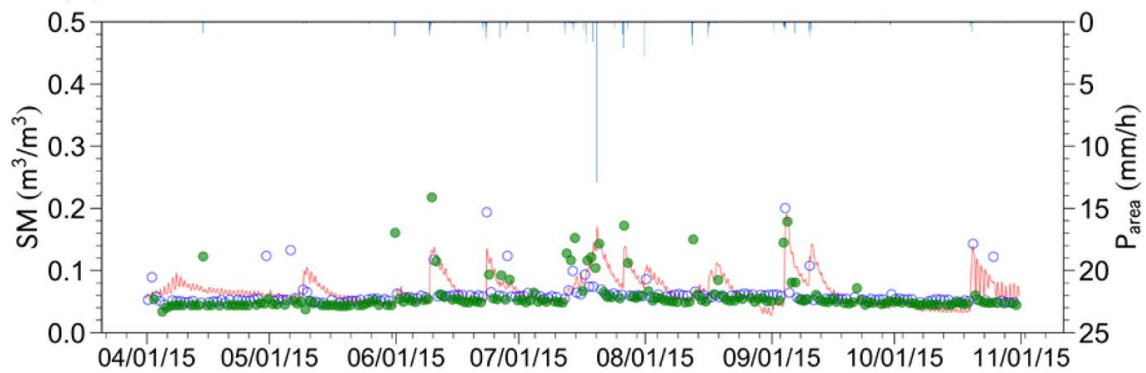

(e) - In situ $\mathrm{SM}_{\text {area }}(3 \mathrm{~cm} \mathrm{d)} \circ$ AMSR2(A) $\quad$ AMSR2(D)

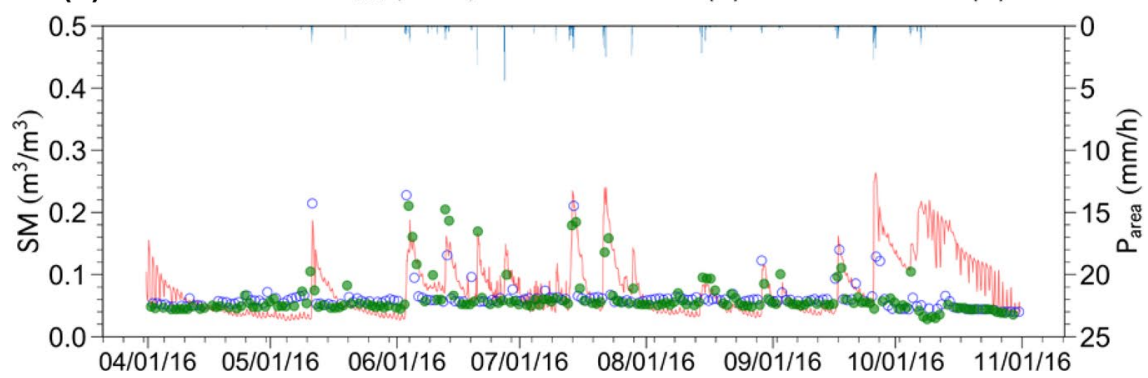


Fig. 5 (continued)
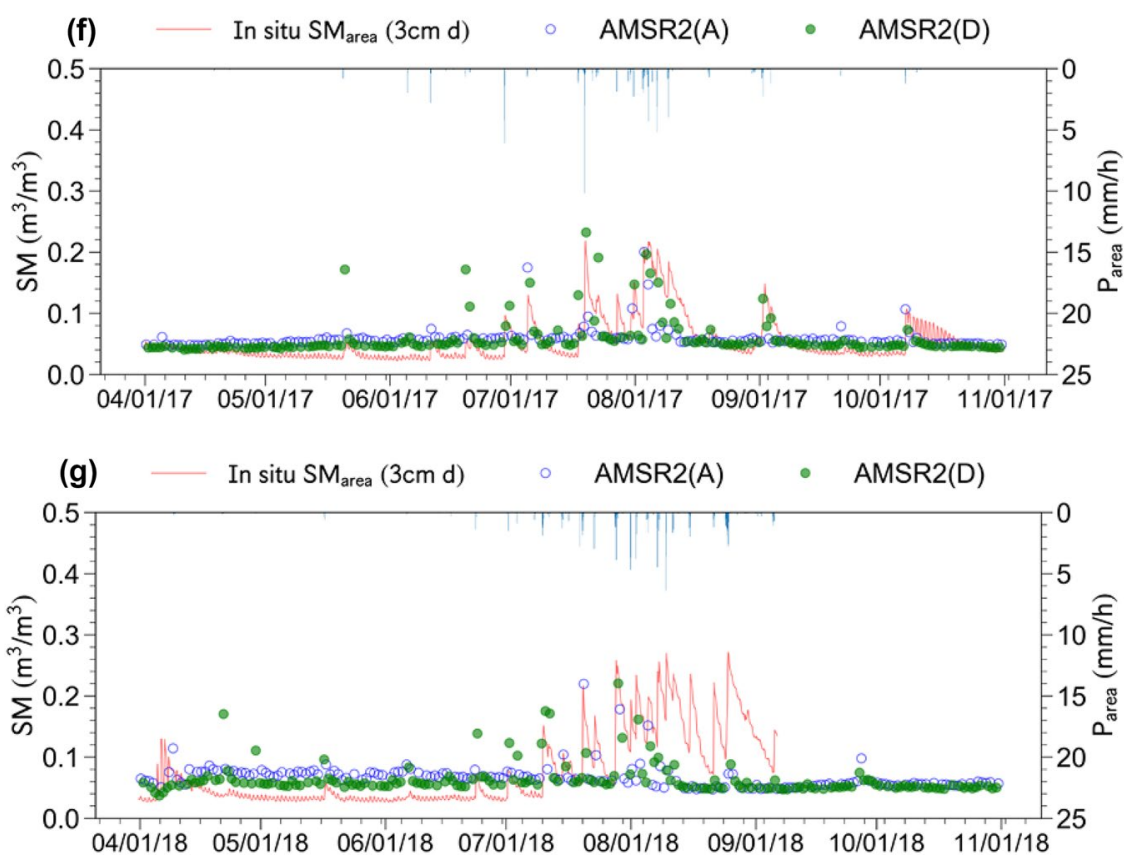

could result in a decrease in the accuracy of AMSR2 soil moisture measurements.

Overall, satisfactory correspondence has been observed in the response pattern, and the difference between the AMSR2 soil moisture data and the in situ soil moisture content at 3-cm depth has not been particularly large for 7 years, implying that AMSR2 could measure soil moisture as accurately and reliably as AMSR-E [21].

\subsection{Measurement accuracy of AMSR2}

Figure 6 illustrates the relationship between AMSR2 soil moisture from descending orbits and in situ soil moisture at 3-cm depth. This figure was drawn using data only from the period with unfrozen soil (May-September) to eliminate AMSR2 soil moisture measurements affected by freezing and thawing of the soil [29]. As mentioned earlier, AMSR2 soil moisture measurement from descending orbits is better than from ascending orbits. Therefore, the AMSR2 soil moisture measurements from descending orbits were considered in further discussion of measurement accuracy.

The data plotted in Fig. 6 are scattered mostly around the 1:1 line, and the AMSR2 soil moisture data vary with in situ soil moisture content. Careful inspection of Fig. 6 reveals the greatest amount of scatter illustrated is in relation to 2018 (Fig. $6 \mathrm{~g}$ ), especially in the higher range of in situ soil moisture, which is an indication of the poor accuracy of AMSR2 soil moisture measurements. Figure 6 presents obvious underestimation of the AMSR2 soil moisture measurements except for 2017 (Fig. 6f). The causes of this underestimation are discussed later.
To discuss more precise measurement accuracy and performance capability, it is informative to compare AMSR2 L2 and SMOS L2 soil moisture products. Some earlier studies have evaluated the SMOS L2 soil moisture product in Spain [30] and North America [31], reporting high-measurement accuracy with RMSEs of $<0.05 \mathrm{~m}^{3} / \mathrm{m}^{3}$. To obtain more reliable data from the SMOS soil moisture products (ver. 650: the latest version as of December 2018), this evaluation was made on the condition that the data existence rate of successfully retrieved sampling points was $>60 \%$ in $M 1$. The used data were checked based on the value of the parameter RFI_Prob [32] and those for which then value of RFI_Prob was $>0.6$ were removed.

Figure 7 shows the temporal changes of AMSR2 (descending: around 03:00 local time) and SMOS (ascending: around 06:00 local time) soil moisture in 2013, 2015, 2017 and 2018, when the climatic conditions were important and/or representative. Unfortunately, there were insufficient SMOS data for full comparison with AMSR2 because of an inappropriate revisit time (i.e., not daily) over M1 [23]. However, difference between AMSR2 and SMOS is evident in terms of the pattern of change and the magnitude of the values. Although the difference between both satellites in 2015 and 2017 is unremarkable, the values of SMOS soil moisture vary more widely than AMSR2 in both 2013 and 2018. If anything, SMOS performed better than AMSR2 in reflecting the hydrological decrease in soil moisture after the peak. SMOS detected physical soil moisture both during and after rainfall in mid-July to early August 2013 (Fig. 7a), mid-August to early September 2018 (Fig. 7d), and during soil freezing/melting in mid-April/ 
Fig. 6 Relationship between in situ area-averaged soil moisture (SM area $)$ and AMSR2(D) soil moisture (SM) in M1 from 2012 to 2018 (D: descending) (a) 2012

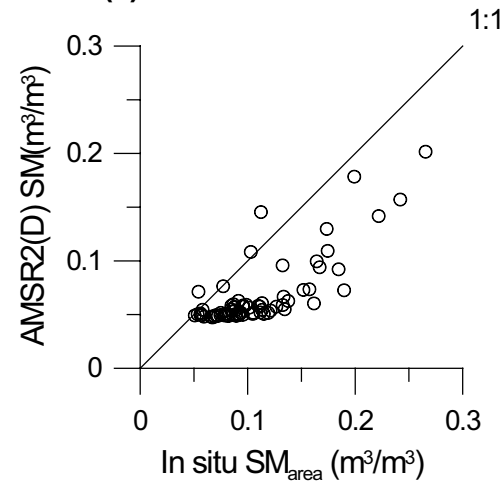

(b) 2013

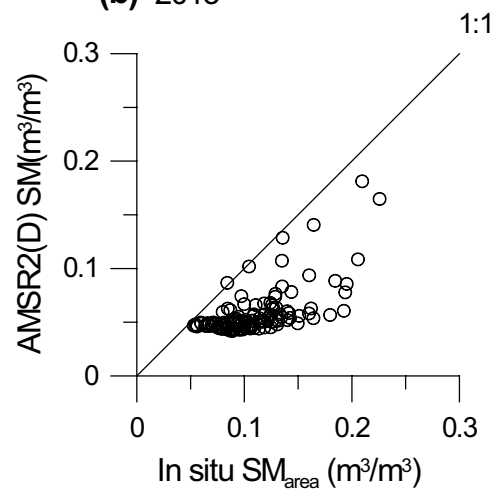

(c) 2014

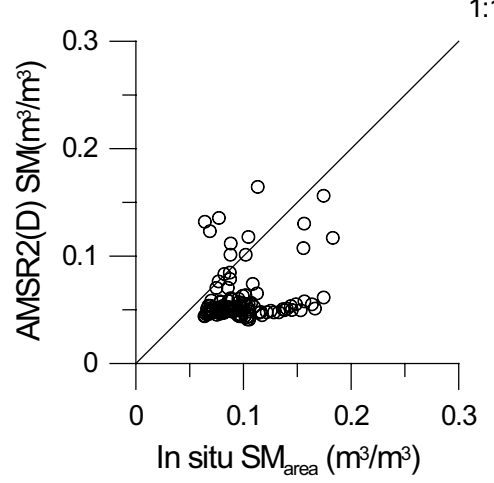

(d) 2015

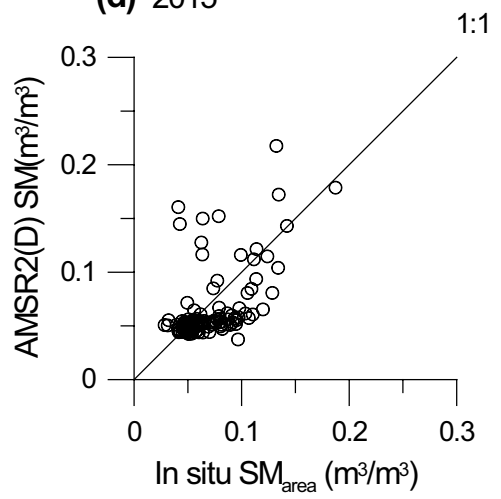

(e) 2016

1:1

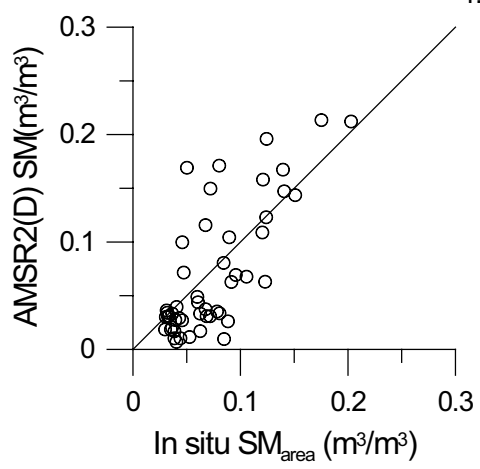

(f) 2017

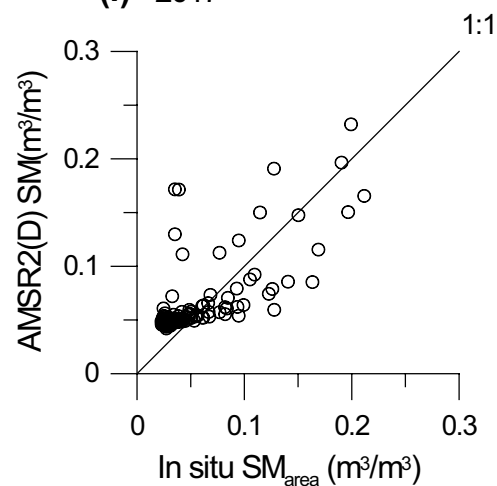

(g) 2018

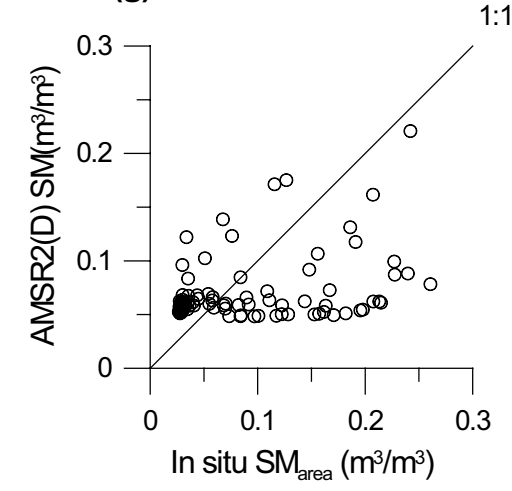


Fig. 7 Comparison of AMSR2 and SMOS soil moisture from descending orbits with in situ area-averaged soil moisture $\left(\mathrm{SM}_{\text {area }}\right)$ at 3-cm depth and area-averaged rainfall $\left(P_{\text {area }}\right)$ in $M 1(2013,2015,2017$, and 2018). Red solid line: in situ area-averaged soil moisture, green solid circle: AMSR2 soil moisture from descending orbits, purple open circle: SMOS soil moisture from ascending orbits

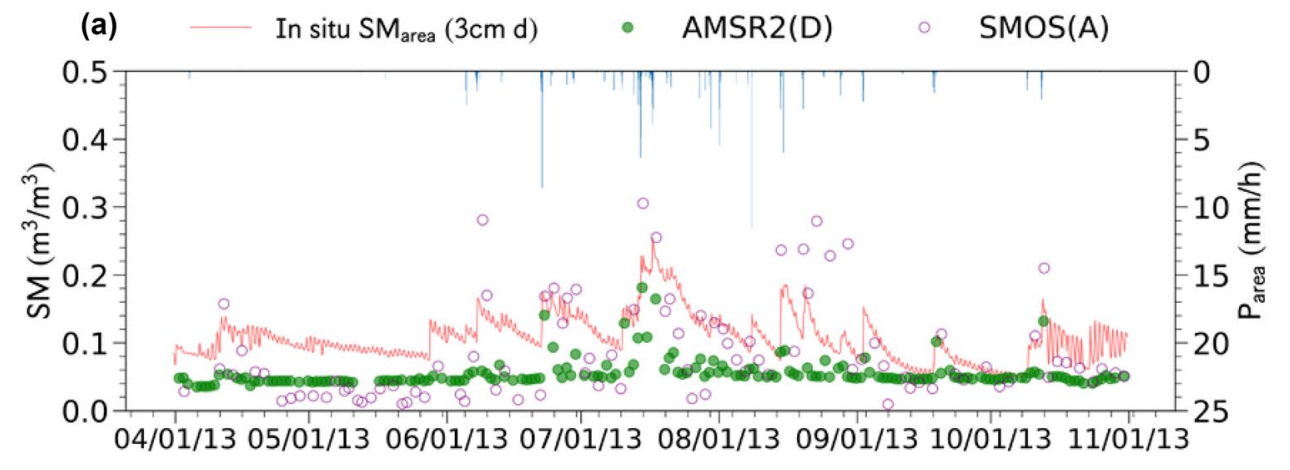

(b) In situ SMarea $(3 \mathrm{~cm} \mathrm{~d}) \quad$ AMSR2(D) $\quad$ SMOS(A)

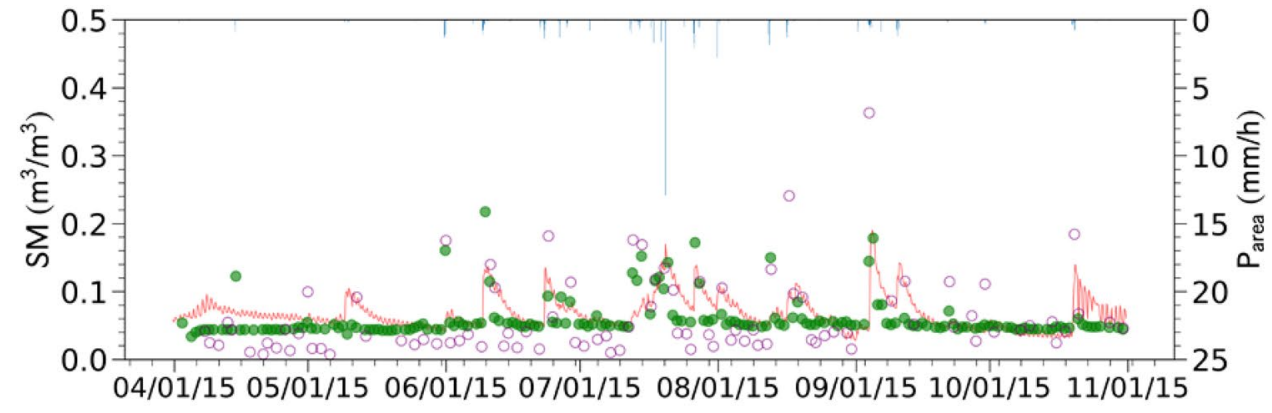

(c) In situ SMarea $(3 \mathrm{~cm} \mathrm{~d}) \quad$ AMSR2(D) $\quad$ SMOS(A)


October 2013 (Fig. 7a) and late October 2015 (Fig. 7b), whereas reasonable measurements were not obtained by AMSR2.

The poor response of AMSR2 on the descending orbit during and after periods of soil freezing is because soil moisture is measured after midnight, i.e., when the soil is frozen in M1. As can be seen in Fig. 5b, f, g, AMSR2 on the ascending orbit (i.e., daytime overflight) was mostly reasonable in measuring in situ soil moisture in cases of soil freezing/melting. This reflects the advantage of AMSR2 in acquiring soil moisture measurements, which is afforded by its daily observational schedule [5].

The measurement accuracy of the AMSR2 L2 soil moisture products was investigated systematically using 
statistical analyses, as represented by the comparative results for AMSR2 and SMOS listed in Table 3, as well as the data acquired in the months with unfrozen soil (May-September) shown in Fig. 6. According to the bias values in Table 3, the soil moisture content from AMSR2 is underestimated slightly; however, these values are nearly equal to those obtained during a validation case study in Australia [10]. At 3-cm depth, the RMSE of AMSR2 varies with year; the values range from 0.028 to $0.071 \mathrm{~m}^{3} / \mathrm{m}^{3}$ on the ascending orbits and from 0.028 to $0.063 \mathrm{~m}^{3} / \mathrm{m}^{3}$ on the descending orbits. The mean value of the RMSE on the descending orbit of AMSR2 is $0.042 \mathrm{~m}^{3} / \mathrm{m}^{3}$. The significant $R$ (correlation coefficient of the linear regression line) values suggest the data are mostly well correlated. The RMSEs of AMSR2 are slightly smaller than obtained for AMSR-E [21]. Although the RMSE values of SMOS are approximately the same as AMSR2, they vary obviously with year and the differences are slightly smaller than those of AMSR2 (Table 3).

The values for both satellites in 2013 (Table 3) are not as good as in other years. It is shown in Table 2 that the amount of rainfall in 2013 was the greatest of all the studied years. The RMSE of AMSR2 on the descending orbit is best in 2015, the year with least rainfall. The RMSEs of AMSR2 on the descending orbit in the wet years (2012, 2013 and 2018) are greater than in the dry years (2014 and 2015). Conversely, the values of bias in the dry years are obviously smaller than in the wet years. Abundant rainfall promotes wet conditions of a thin surface layer of soil and temporary pooling on the soil surface, as well as active development of vegetation that increases the possibility of free water on plants [28] as mentioned above. These conditions could potentially influence AMSR2 measurements of surface soil moisture because in situ soil moisture change can be considered driven by rainfall conditions. However, Table 3 indicates that SMOS does not depend remarkably on such rainfall conditions because it uses a single lower frequency $(1.4 \mathrm{GHz})$ that can measure deeper than AMSR2. The rainfall effects are probably associated with the use of the 10- and 36-GHz frequencies (see Eq. 2). In particular, the shallower detection depth of the $36-\mathrm{GHz}$ frequency of AMSR2 can be supposed easily affected by such rainfall conditions. These factors lead to the annual variation of the RMSE and bias of AMSR2. More insightful discussion could not be based on the findings of this study because of insufficient data concerning the conditions of the upper thin $(0-5 \mathrm{~cm})$ layer of soil in M1. However, it is established that the RMSE is improved under conditions of low rainfall.

The values of bias of AMSR2 in Table 3 are negative (except for 2017), which means AMSR2 generally underestimates soil moisture. Although, as shown in 2.3, the AMSR2 algorithm eliminates the effects by the frequency difference, the values of brightness temperature and the normalized difference vegetation index (NDVI) themselves are affected directly by surface soil temperature and vegetation development, respectively. Thus, the effects of soil temperature and vegetation $[18,33,34]$ should be considered possible causes of the underestimation.

Figure 8 shows the relationship between the area-averaged in situ soil temperature at 3-cm depth at the time of AMSR2 soil moisture measurement and the AMSR2 soil moisture during periods of no rainfall in 2013 (wet year) and 2015 (dry year). The area-averaged in situ soil temperature data, measured horizontally using a platinum resistance temperature sensor (Climatec C-PTWP), are obtained from all the stations listed in Table 1. There is no
Table 3 Evaluation results of L2 soil moisture products of AMSR2 and SMOS at 3-cm depth during the period from May to September in each year (2012-2018)

\begin{tabular}{llllllllll}
\hline Sensor_Year & RMSE & BIAS & R & N & Sensor_Year & RMSE & BIAS & R & N \\
\hline AMSR2(A)_2012 & 0.058 & -0.049 & 0.68 & 72 & SMOS(A)_2012 & 0.064 & 0.004 & 0.78 & 72 \\
AMSR2(A)_2013 & 0.071 & -0.061 & 0.3 & 123 & SMOS(A)_2013 & 0.063 & -0.02 & 0.66 & 72 \\
AMSR2(A)_2014 & 0.034 & -0.016 & 0.54 & 132 & SMOS(A)_2014 & 0.043 & -0.008 & 0.54 & 76 \\
AMSR2(A)_2015 & 0.028 & -0.012 & 0.39 & 130 & SMOS(A)_2015 & 0.058 & -0.002 & 0.37 & 70 \\
AMSR2(A)_2016 & 0.041 & -0.01 & 0.41 & 126 & SMOS(A)_2016 & 0.032 & -0.002 & 0.84 & 81 \\
AMSR2(A)_2017 & 0.032 & 0.004 & 0.53 & 124 & SMOS(A)_2017 & 0.044 & 0.01 & 0.68 & 76 \\
AMSR2(A)_2018 & 0.065 & -0.014 & 0.13 & 106 & SMOS(A)_2018 & 0.027 & -0.012 & 0.93 & 64 \\
AMSR2(D)_2012 & 0.05 & -0.041 & 0.79 & 73 & SMOS(D)_2012 & - & - & - & 2 \\
AMSR2(D)_2013 & 0.058 & -0.051 & 0.64 & 126 & SMOS(D)_2013 & 0.069 & -0.015 & 0.58 & 39 \\
AMSR2(D)_2014 & 0.031 & -0.012 & 0.38 & 133 & SMOS(D)_2014 & 0.05 & -0.014 & 0.51 & 53 \\
AMSR2(D)_2015 & 0.028 & -0.005 & 0.56 & 133 & SMOS(D)_2015 & 0.042 & -0.011 & 0.72 & 46 \\
AMSR2(D)_2016 & 0.036 & -0.001 & 0.59 & 128 & SMOS(D)_2016 & 0.039 & -0.005 & 0.76 & 50 \\
AMSR2(D)_2017 & 0.031 & 0.011 & 0.72 & 123 & SMOS(D)_2017 & 0.033 & 0.001 & 0.81 & 49 \\
AMSR2(D)_2018 & 0.063 & -0.012 & 0.38 & 105 & SMOS(D)_2018 & 0.039 & -0.007 & 0.81 & 55 \\
\hline
\end{tabular}

Unit of RMSE and Bias: $\mathrm{m}^{3} / \mathrm{m}^{3}$; R: the correlation coefficient of the linear regression line; $\mathrm{N}$ : the number of data; (A) ascending; (D) descending 


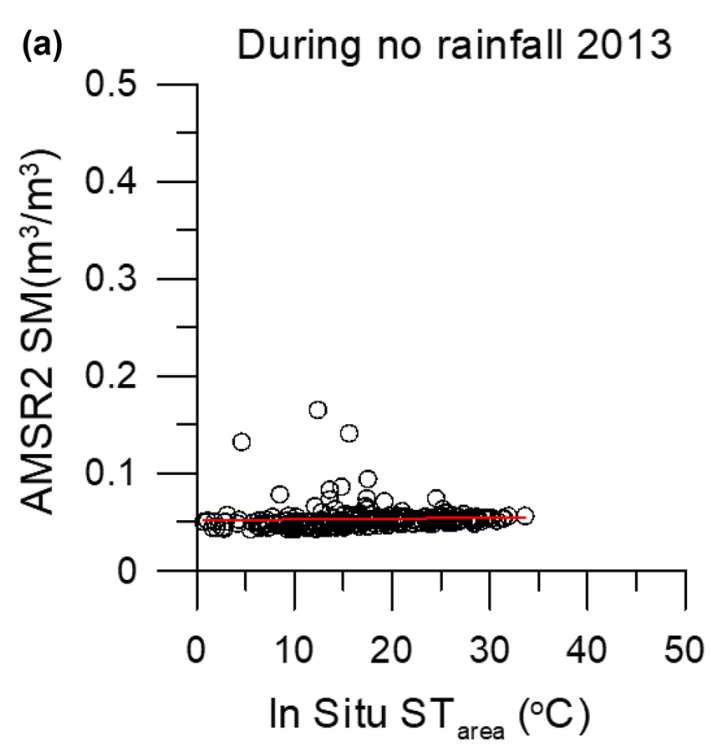

(b) During no rainfall 2015

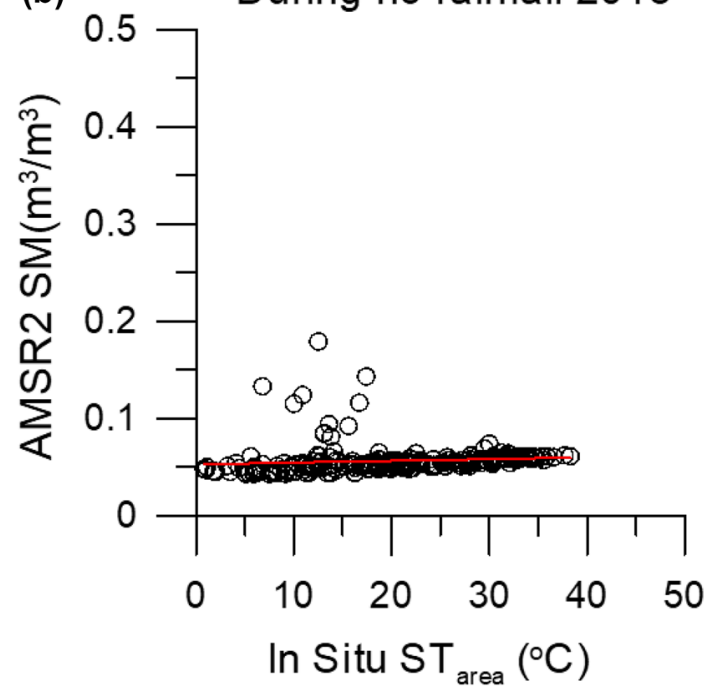

Fig. 8 Relationship between the area-averaged situ soil temperature at 3-cm depth (ST area) and AMSR2 soil moisture (SM) in M1: red line shows the linear regression line

remarkable decrease or increase in AMSR2 soil moisture with the increase in soil temperature within the range of $0-40^{\circ} \mathrm{C}$ at $3-\mathrm{cm}$ depth. Although these two factors are not correlated, Fu et al. [18] highlighted the potential effect of soil temperature based on analysis of the surface soil temperature. The same results were obtained in other years.

The monthly averaged value change of the NDVI from 2012 to 2018 in M1 is illustrated in Fig. 9 using the NDVI product data (MOD13A3, 0.05 deg, ver. 6) of the Terra MODIS (Moderate Resolution Imaging Spectroradiometer) [35]. This figure indicates poor plant development in April and May, commencement of plant development in June, and well-developed plants in August. According

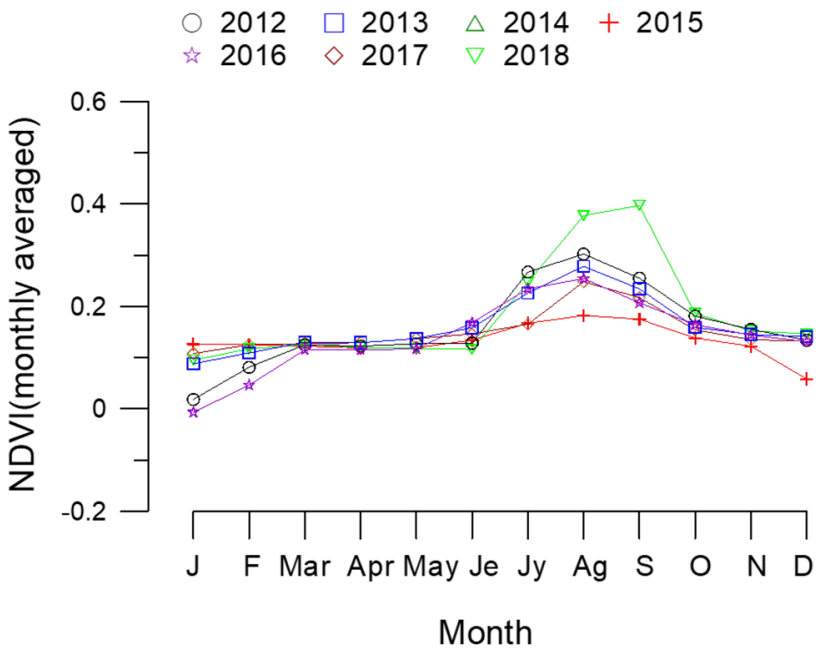

Fig. 9 A time series of monthly averaged NDVI change in every year from 2012 to 2018 in M1

to observers of the National Agency for Meteorology and Environment (NAMEN) at the MGS and DRS monitoring stations, the ground surface in M1 since 2000 tends to be characterized by an almost complete cover of bare soil in April-May and by mixed bare soil, short glass and sporadic shrubs in summer (personal communications). Figure 10 illustrates the relation of monthly averaged NDVI to AMSR2 soil moisture on descending orbits in 2013 and 2015. As AMSR2 soil moisture change at a constant value of NDVI is evident in this figure, no specific relationship could be discerned between the two (analysis of other years showed the same result). Therefore, soil temperature



Fig. 10 Relationship between monthly averaged NDVI and monthly averaged AMSR2 soil moisture (SM) in 2013 and 2015 in M1 
change and vegetation development can be considered not to influence the underestimation of AMSR2 soil moisture measurement.

Similar to AMSR2, the bias values of SMOS (Table 3) are mostly negative, which means the SMOS measurements of soil moisture are generally underestimated. However, as the values are relatively smaller and vary within a smaller range in comparison with those of AMSR2, it appears that SMOS is able to measure soil moisture more effectively than AMSR2, which measures soil moisture at a shallower depth. Fu et al. [18] attempted to validate AMSR2 soil moisture measurements using in situ soil moisture at the depth of $2.5 \mathrm{~cm}$ in a crop field. Their results produced a value of negative bias $\left(-0.094 \mathrm{~m}^{3} / \mathrm{m}^{3}\right)$ slightly larger than determined in this study (Table 3 ). In reality, as the value of bias depends on rainfall conditions, it could be considered that there is difference between the depth of AMSR2 observations and in situ soil moisture measurements, as highlighted by $[17,20]$. Thus, a possible cause of the underestimation of AMSR2 measurements could be the sampling depth that is shallower than $3 \mathrm{~cm}$.

The results in this section indicate best agreement between in situ soil moisture content at $3-\mathrm{cm}$ depth and AMSR2 soil moisture measured on descending orbits. Accordingly, although the RMSE value is affected by rainfall conditions and the AMSR2 soil moisture measurements are underestimates because of the difference in soil moisture sampling depths, it is likely that AMSR2 could measure surface soil moisture in steppe areas with highmeasurement accuracy of $<0.05 \mathrm{~m}^{3} / \mathrm{m}^{3}$.

\section{Conclusions}

The AMSR2 L2 soil moisture product (ver. 3) has provided a reasonable match in terms of the response pattern of in situ soil moisture and its value since 2012. The values of RMSE and bias on the descending orbits varied from 0.028 to $0.063 \mathrm{~m}^{3} / \mathrm{m}^{3}$ (mean value: $0.042 \mathrm{~m}^{3} / \mathrm{m}^{3}$ ) and from 0.011 to $-0.001 \mathrm{~m}^{3} / \mathrm{m}^{3}$, respectively, with regard to the relationship between AMSR2 L2 soil moisture and in situ soil moisture at 3-cm depth. The values of RMSE and bias of AMSR2 soil moisture measurements in M1 were found better in cases of low rainfall, and they were unaffected either by change of soil temperature at $3-\mathrm{cm}$ depth or by surface vegetation. Thus, AMSR2 could be considered capable of estimation of average surface soil moisture content with high accuracy $\left(<0.05 \mathrm{~m}^{3} / \mathrm{m}^{3}\right)$ and observation of surface soil moisture with accuracy and stability equivalent to SMOS. Although AMSR2 has been underestimating soil moisture because of the non-optimal measurement depth of in situ soil moisture, the AMSR2 L2 soil moisture product has been shown to have high quality, and it has proven useful for large-scale monitoring of surface soil moisture in grassland areas. For improved measurement of soil moisture, evaluations will be required using adequate datasets of in situ soil moisture measurements at an effective measurement depth, from other validation sites with different surface conditions [36], and using other soil moisture products such as the LPRM $[17,18]$.

Acknowledgements This study was supported as a joint project (JXPSPC-454881) between the University of Tsukuba and JAXA. It was conducted through close collaboration with Ganjuur Sarantuya (project management), Gombo Davaa (field observation support), Misako Kachi (support with AMSR2 soil moisture measurement research), Toshio Koike (active cooperation with soil moisture measurement analysis) and the Edanz editing service (English proofreading of the manuscript). Comments from the anonymous reviewers were found very helpful for improving the manuscript.

\section{Compliance with ethical standards}

Conflict of interest The authors declare that they have no conflict of interests.

Open Access This article is distributed under the terms of the Creative Commons Attribution 4.0 International License (http://creativeco mmons.org/licenses/by/4.0/), which permits unrestricted use, distribution, and reproduction in any medium, provided you give appropriate credit to the original author(s) and the source, provide a link to the Creative Commons license, and indicate if changes were made.

\section{References}

1. Beljaars ACM, Viterbo P, Miller MJ, Betts AK (1996) The anomalous rainfall over the United States during July, 1983: sensitivity to land surface parameterization and soil moisture anomalies. Mon Weather Rev 124:362-383. https://doi.org/10.1175/15200493(1996)124<0362:TAROTU>2.0.CO;2

2. NASA (2018) Aqua project science. https://aqua.nasa.gov/\#. Accessed 22 Dec 2018

3. Kerr $\mathrm{YH}$, Waldteufel $\mathrm{P}$, Richaume $\mathrm{P}$, Wigneron J-P, Ferrazzoli $\mathrm{P}$, Mahmoodi A, Bitar AA, Cabot F, Gruhier C, Juglea CE, Leroux D, Mialon A, Delwart S (2012) The SMOS soil moisture retrieval algorithm. IEEE Trans Geosci Remote Sens 50:1384-1403. https ://doi.org/10.1109/TGRS.2012.2184548

4. Imaoka K, Kachi M, Fujii $\mathrm{H}$, Murakami $\mathrm{H}$, Hori $\mathrm{M}$, Ono A, Igarashi T, Nakagawa K, Oki T, Honda Y, Shimoda H (2010) Global Change Observation Mission (GCOM) for monitoring carbon, water cycles, and climate change. Proc IEEE 98:717-734

5. JAXA (2019) About AMSR2. https://suzaku.eorc.jaxa.jp/ GCOM_W/w_amsr2/whats_amsr2.html. Accessed 06 June 2019

6. Rasmy M, Koike T, Xin L (2014) Applicability of multi-frequency passive microwave observations and data assimilation methods for improving numerical weather forecasting in Niger, Africa. Remote Sens 6:5306-5324. https://doi.org/10.3390/rs6065306

7. Sawada Y, Koike T (2016) Towards ecohydrological drought monitoring and prediction using a land data assimilation system: a case study on the Horn of Africa drought (2010-2011). J Geophys Res Atmos 121:8229-8242. https://doi.org/10.1002/2015J D024705 
8. Kawanishi T, Sezai T, Ito Y, Imaoka K, Takeshima T, Ishido Y, Shibata A, Miura M, Inahata H, Spencer RW (2003) The Advanced Microwave Scanning Radiometer for the Earth Observing System (AMSR-E): NASDA's contribution to the EOS for global energy and water cycle studies. IEEE Trans Geosci Remote Sens 41:184-194. https://doi.org/10.1109/TGRS.2002.808331

9. L'Ecuyer TS, Jiang JH (2010) Touring the atmosphere aboard the A-Train. Phys Today 63:36-41. https://doi.org/10.1063/1.346362

10. Yee M, Walker JP, Dumedah G, Monerris A, Rüdiger C (2013) Towards land surface model validation from using satellite retrieval soil moisture. In: Proceedings of MODSIM2013 20th international conference on modelling and simulation, Adelaide, Australia, December 1-6, pp 2890-2896

11. Smith A, Walker JP, Western A, Young R, Ellet K, Pipunic R, Grayson R, Siriwardena Chiew F, Richter H (2012) The Murrumbidgee soil moisture monitoring network data set. Water Resour Res 48:W07701. https://doi.org/10.1029/2012WR011976

12. Cho E, Moon H, Choi M (2015) First assessment of the Advanced Microwave Scanning Radiometer 2 (AMSR2) soil moisture contents in Northeast Asia. J Meteorol Soc Jpn Ser II 93:117-129. https://doi.org/10.2151/jmsj.2015-008

13. Parinussa RM, Holmes TR, Wanders N, Dorigo WA, De Jeu RA (2015) A preliminary study towards consistent soil moisture from AMSR2. J Hydrometeorol 16:932-947. https://doi. org/10.1175/JHM-D-13-0200.1

14. Kim S, Liu Y, Johnson FM, Parinussa RM, Sharma A (2015) A global comparison of alternate AMSR2 soil moisture products: why do they differ? Remote Sens Environ 161:43-62. https://doi. org/10.1175/JHM-D-13-0200.1

15. Zeng J, Li Z, Chen Q, Bi H, Qiu J, Zou P (2015) Evaluation of remotely sensed and reanalysis soil moisture products over the Tibetan Plateau using in situ observations. Remote Sens Environ 163:91-110. https://doi.org/10.1016/j.rse.2015.03.008

16. Wu Q, Liu H, Wang L, Deng C (2016) Evaluation of AMSR2 soil moisture products over the contiguous United States using in situ data from the International Soil Moisture Network. Int J Appl Earth Obs Geoinf 45:187-199. https://doi.org/10.1016/j. rse.2015.03.008

17. Bindlish $R$, Cosh $M H$, Jackson TJ, Koike $T$, Fujii H, Chan SK, Asanuma J, Berg A, Bosch DD, Caldwell T, Collins $\mathrm{CH}$, McNairn $\mathrm{H}$, Martínez-Fernández J, Prueger J, Rowlandson T, Seyfried $M$, Starks P, Thibeault M, Van der Velde R, Walker JP, Coopersmith EJ (2018) GCOM-W AMSR2 soil moisture product validation using core validation sites. IEEE J Sel Top Appl Earth Obs Remote Sens 11:209-218. https://doi.org/10.1109/JSTARS.2017.2754293

18. Fu H, Zhou T, Sun C (2019) Evaluation and analysis of AMSR2 and FY3B soil moisture products by an in situ network in cropland on pixel scale in the Northeast of China. Remote Sens 11:868. https://doi.org/10.3390/rs11070868

19. Engman ET, Gurney RJ (1991) Remote sensing in hydrology. Chapman and Hall, London. ISBN 0-412-24450-0

20. Escorihuela MJ, Chanzy A, Wigneron JP, Kerr YH (2010) Effective soil moisture sampling depth of L-band radiometry: a case study. Remote Sens Environ 114:995-1001. https://doi. org/10.1016/jrse.2009.12.011

21. Kaihotsu I, Koike T, Yamanaka T, Fujii H, Ohta T, Tamagawa K, Oyunbaatar D, Akiyama R (2009) Validation of soil moisture estimation by AMSR-E in the Mongolian Plateau. J Remote Sens Soc Jpn 29:271-281. https://doi.org/10.11440/rssj.29.271

22. MEXT (Ministry of Education, Culture, Sports, Science, and Technology of Japan) (2018) Development of next coming Advanced Microwave Scattering Radiometer (AMSR3). https://www8. cao.go.jp/space/committee/27-kiban/kiban-dai43/pdf/siryo u5-pdf\#search=\%27AMSR3\%27. Accessed 06 June 2019
23. Kaihotsu I, Fujii H, Oyunbaatar D, Yamanaka T, Shiraishi K, Koike T (2013) First evaluation of SMOS L2 soil moisture products using in situ observation data of MAVEX on the Mongolian Plateau in 2010 and 2011. Hydrol Res Lett 7:30-35. https://doi. org/10.3178/HRL.7.30

24. IMKO (2017) Manual TRIME-PICO 64/32

25. JAXA (2013) Descriptions of GCOM-W1 AMSR2 level $1 R$ and level 2 algorithms. https://suzaku.eorc.jaxa.jp/GCOM_W/data/doc/ NDX-120015A.pdf. Accessed 22 April 2019

26. Koike T, Nakamura Y, Kaihotsu I, Davaa G, Matsuura N, Tamagawa K, Fujii H (2004) Development of an Advanced Microwave Scanning Radiometer (AMSR-E) algorithm of soil moisture and vegetation water content. Annu J Hydraul Eng JSCE 48:217-222. https://doi.org/10.2208/prohe.48.217

27. Fujii H, Koike T, Imaoka K (2009) Improvement of the AMSR-e algorithm for soil moisture estimation by introducing a fractional vegetation coverage dataset derived from MODIS data. J Remote Sens Soc Jpn 29:282-292. https://doi.org/10.11440/ rssj.29.282

28. Hornbuckle BK, England AW, Anderson MC (2007) The effect of intercepted precipitation on the microwave emission of maize at 1.4 GHz. IEEE Trans Geosci Remote Sens 50:1544-1555. https ://doi.org/10.1109/TGRS.2007.894057

29. Entekhabi D, Njoku EG, O'Neill PE, Kellogg KH, Crow WT, Edelstein WN, Entin JK, Goodman SD, Jackson TJ, Johnson J, Kimball J, Piepmeier JR, Koster RD, Martin N, McDonald KC, Moghaddam M, Moran S, Reichle R, Shi JC, Spencer MW, Thurman SW, Tsang L, Van Zyl J (2010) The soil moisture active passive (SMAP) mission. Proc IEEE 98(5):704-716. https://doi.org/10.1109/JPROC .2010 .2043918

30. Sánchez N, Martínez-Fernández J, Scaini A, Pérez-Gutiérrez C (2012) Validation of the SMOS L2 soil moisture data in the REMEDHUS network (Spain). IEEE Trans Geosci Remote Sens 50:1602-1611. https://doi.org/10.1109/TGRS.2012.2186971

31. Jackson TJ, Bindlish R, Cosh MH, Zhao T, Starks PJ, Bosch DD, Seyfried M, Moran MS, Goodrich DC, Kerr YH, Leroux D (2012) Validation of Soil Moisture and Ocean Salinity (SMOS) soil moisture over watershed networks in the U.S. IEEE Trans Geosci Remote Sens 50:1530-1543. https://doi.org/10.1109/TGRS.2011.21685 33

32. Rodríguez-Fernández NR, Kerr $\mathrm{YH}$, Van der Schalie R, Yaari $A$, Wigneron JP, De Jeu R, Richaume P, Dutra E, Mialon A, Drusch $M$ (2016) Long term global surface soil moisture fields using an SMOS-trained neural network applied to AMSR-E data. Remote Sens 8:959-985. https://doi.org/10.3390/rs8110959

33. Guo Y, Shi J, Mao K (2007) Surface temperature effect on soil moisture retrieval from AMSR-E. In: Proceedings of IEEE international geoscience and remote sensing symposium, IGARSS 2007, pp 1192-1195. https://doi.org/10.1109/igarss.2007.4423018

34. Zhao T, Shi J, Bindlish R, Jackson T, Cosh M, Jiang L, Zhang Z, Lan H (2015) Parametric exponentially correlated surface emission model for L-bandpassive microwave soil moisture retrieval. Phys Chem Earth 83-84:65-74. https://doi.org/10.1016/j. pce.2015.04.001

35. MODIS (2019) MODIS Vegetation Index Products (NDVI and EVI). https://modis.gsfc.nasa.gov/data/dataprod/mod13.php/. Accessed 10 Sept 2019

36. Jackson TJ, Bindlish R, Cosh M (2009) Validation of AMSR-E soil moisture products using in situ observations. J Remote Sens Soc Jpn 29:263-270. https://doi.org/10.11440/rssj.29.263

Publisher's Note Springer Nature remains neutral with regard to jurisdictional claims in published maps and institutional affiliations. 